\title{
Ex Obra, la rematerialización de la imagen en movimiento
}

\section{Di Bella, Daniela V. [ver currículum del autor, docente de la Facultad de Diseño y Comunicación]}

Resumen: Este escrito aborda los aspectos que hacen a lo experimental en relación con los aspectos estéticos y sensoriales.

Palabras clave: Posmodernidad Cultura - Imagen en movimiento Experimental - Paracinema Rematerialización - New Media Estética - Sensorialidad Óptico/Háptico.

$\left(^{*}\right)$ Arquitecta. Magister en Diseño. Phd en Educación Superior (nivel tesis). Responsable de Producción DCUP. Docente de Maestría y

Doctorado en Diseño de la facultad de Diseño y Comunicación de la Universidad de Palermo.

Paracinema una relación sensorial con el objeto estético
Cuadernos del Centro de Estudios de Diseño y Comunicación Nº 66

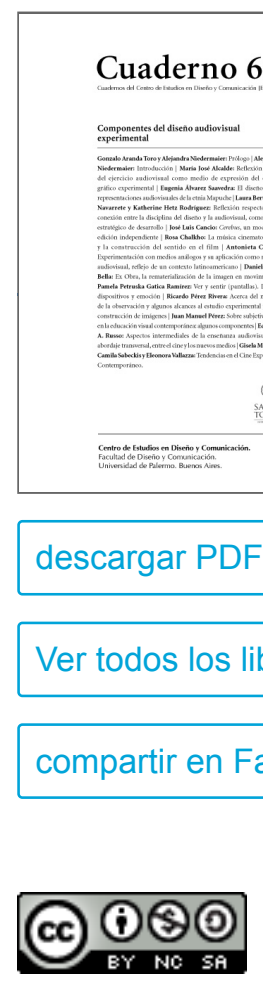

ISSN: 1668-0227

Componentes del diseño audiovisual experimental

Año XVIII, Marzo 2018, Buenos Aires, Argentina | 196 páginas

\section{UP}

\section{ver índice de la publicación}

bros de la publicación

acebook

Esta obra está bajo una Licencia Creative Commons Atribución-NoComercialCompartirlgual 4.0 Internacional

"Al respecto Deleuze afirma ...Ariadna se ha ahorcado... la obra de arte abandona el reino de la representación para hacerse experiencia (o experimento), empirismo trascendental o ciencia de lo sensible..." (Rachjman, 2004, p. 124)

Este artículo abre con una cita de Gilles Deleuze que hace referencia a un estado del arte, que supera el concepto de crítica, al de clínica de la buena salud de la obra de arte o... "quitarle a la estética su ropaje de tribunal y de juicio y hacer de ella un juego afirmativo de experimentación y novedad conceptual (...) una "voluntad de arte" que tiene "que ver siempre con la aparición de algo nuevo y singular" "...que supone una condición no trascendental sino experimental". (Rachjman, 2005, p. 119)

La estética experimental y de vanguardia artística es y ha sido uno de los aspectos más exigentes y estimulantes de los estudios históricos y actuales acerca de la imagen en movimiento y medios de 
comunicación. Las razones se vinculan posiblemente con los usos expresivos que la contemporaneidad viene plasmando en sus realizaciones - desde el advenimiento de las medias tradicionales ahora digitales- las que desafían y desarticulan las nociones de la subjetividad, la expectación y el uso del soporte o media, lo que deriva en un tipo de creación amplificada, que comparte miradas y cruces con otras disciplinas, como el arte, el diseño, la filosofía, la cultura, la sociología y la psicología entre otras. Lo que para algunos es la amplificación del campo, para otros como Akira Lippit son por el contrario exploraciones que estarían por fuera de los límites de lo que se entiende de manera tradicional -algo así como una creación por fuera del espacio de trabajo-, dando entonces con una "ex" obra. Casi como si fuera un juego de palabras, la creación y producción de una obra experimental existe simultáneamente dentro y fuera del campo de las realizaciones y, al exponer tan al desnudo sus modos de producción, permite y posibilita las experimentaciones del juego con las fronteras y poéticas mediante el uso de todos los recursos alternativos (Akira Lippit, 2012). Sea de una u otra forma la experimentación con la imagen en movimiento opera por fuera de los marcos teóricos convencionales. Al respecto Clara Garavelli expresa que en las prácticas audiovisuales de producción nacional, desde la incorporación del video y las prácticas de new media, estas se relacionan con el ámbito de lo experimental en razón de un contexto de ausencia de legitimación específica, más aun cuando han dejado muy atrás la denominación de videoarte (Garavelli, 2015). De un modo más integrador aunque tradicional y vinculado al cine, Albert Viñas se aproxima a una definición de las prácticas experimentales de imagen en movimiento:

El cine experimental designa un conjunto complejo de prácticas fílmicas heterogéneas que utilizan el medio cinematográfico desde presupuestos artísticos, planteando cuestiones acerca de la naturaleza del propio dispositivo. El término cine experimental resulta ser un vocablo controvertido que identifica un amplio campo de creación de imágenes en movimiento, ubicado entre el espacio representado por la institución cinematográfica y el contexto del arte contemporáneo. La palabra experimental indica un espíritu explorador, un proceso de investigación y de interrogación de las posibilidades del medio, en tanto que herramienta útil para abordar concepciones artísticas. (Viñas, 2008, p. 7)

En definitiva este tipo de prácticas se identifican por un espíritu de contracorriente, que recibirá el nombre de experimental en donde destacan algunas categorías de índole clasificatoria como el poema fílmico, underground cinema, el cine independiente y el alternativo. Dada la relación histórica de pendularidad que ha mantenido el arte con el diseño, desde 1980 se viene asociando al Diseño como una nueva forma de arte, producto de la irrupción de los medios digitales y de la paulatina estetización de la vida cotidiana o lo cotidiano de lo estético favorecida por el desplazamiento de la belleza -atribuida inicialmente al arte- hacia los contextos de consumo masivo:

En el momento en que la estética deja de ser un atributo y una competencia del mundo representado para convertirse en algo propio del mundo construido, aspectos como la relación entre arte y técnica, o entre arte y ciencia, cambian totalmente de sentido. Incluso un concepto como el de imagen deja de tener una connotación negativa que la asimila a la lógica de las apariencias para convertirse en la expresión de una obra en constante evolución obtenida mediante una tecnología que ya no es reproductora o difusora, sino productiva por sí misma. (Calvera, 2005, pp. 1-30)

Según Gianni Vattimo, la historia y la cultura asignaron al arte -como única manifestación- una evidente función estética que se fue diluyendo "es más interesante ver un audiovisual o un spot publicitario que ir a una galería de arte" (Vattimo, 1985). En esta línea Jon Krasner enfatiza la dimensión protagónica que ha tenido la variable 
tiempo, como fuente de experimentación, impacto y expresión artística de las realizaciones desde fines de 1970, debido a la relación que se estableció entre la evolución del diseño gráfico y la tecnología digital. Puntualiza que esta pasó de ser una disciplina bidimensional a otra que incorpora los media de la comunicación en todas sus vertientes: película, animación, sonido, interactividad y diseño ambiental, dentro de un contexto que fusiona TV, internet y entornos inmersivos. Destaca que los media digitales han efectuado un abrupto salto cualitativo, dejando en default a la "era de la información" para pasar a la "era de la comunicación", capitalizada por las exigencias de los mercados y la industria del entretenimiento. Los aspectos de la imagen en movimiento tienen hoy en el Motion Graphics o Motion Design la fusión de la exploración de todos los campos de lo audiovisual, diseño, comunicación, interacción, significación y arte. (Krasner, 2008, pp. 1-27)

Esperanza Collado Sánchez se toma de la definición de paracinema (creada por Ken Jacobs, 1970, EEUU), y argumenta que las expresiones audiovisuales como el cine y el video vienen migrando hacia formas del arte contemporáneo en un camino hacia la desmaterialización del medio. Collado explica que lo experimental de estas prácticas se sitúa por fuera de su dispositivo tradicional de creación, ejecución y recepción, y expresa que la imagen en movimiento se ha desplazado a las salas de exposición, favorecida por la tecnología digital, el resurgimiento de la teatralidad del arte, y una reconfiguración general de la representación visual. Descompone al audiovisual incluyendo al artista y al espectador para recomponerlos en una experiencia conceptual rematerializada

Pueden entenderse como propiedades inherentes al cine, el evento luminoso, el movimiento, el montaje, la modularidad espacio-temporal, la duración y el proceso... la historia de la desmaterialización del medio, contempla la producción de experiencias cinemáticas más allá de su aparato o soporte físico estándar. El modelo sugerido por los artistas conceptuales, que transferían la importancia de la obra a la idea en detrimento del objeto, daba la clave para comprender que ahora la idea de cine es la única maquinaria para producirlo... el material ahora es la experiencia. Pronto todo podría servir de pantalla, desde el cuerpo del artista a los cuerpos de los espectadores, y todo en calidad paracinemática, podía reemplazar al film porque se trataba de trasladar la movilidad cerebral en el tiempo a la movilidad del cuerpo en el espacio (Collado Sánchez, 2012, pp. 23-69)

Breve retrospectiva del origen y motivo de la experimentación

A fines del SXIX el cambio de las condiciones sociales, económicas, culturales y del capitalismo inicial alimentó en los artistas la necesidad de abandonar la representación clásica hacia la expresión del espacio en términos geométricos, en un medio de liberación hacia exploración de lo espontáneo, lo subconsciente y lo irracional. Se abandonaron las leyes de la belleza y la organización social en un intento de demoler la estética y los estándares de arte. Esta ruptura se manifestará en la música, poesía, escultura, pintura, diseño gráfico, y el cine experimental (Krasner, 2008, pp. 1-27). De esta manera a comienzos del 1900, las vanguardias fueron definiendo en poco tiempo una diversidad de modos de lectura y expresiones de la realidad, tendientes cada vez más hacia el subjetivismo, a cuya superposición, velocidad y recursos, la sociedad en general no lograba acomodarse, ni entender en profundidad. El arte del siglo XVIII producto de la imitación y resultado de la discursividad, relato de la historia y la mitología, la naturaleza y la destreza técnica del artista, fue reemplazado paulatinamente por otro que en un primer momento descompuso el color en múltiples partículas, luego en planos, distorsionó la composición perspectívica y el espacio, apoyó búsquedas estéticas de movimiento y sonido en las máquinas, transversalizó contenidos de una sociedad en creciente apertura a la industrialización, ingresó en la psiquis, los sueños y los datos del automatismo psíquico individual y el asociacionismo libre de 
ideas, se internó en la violencia expresiva del dolor de las posguerras en un camino que finalmente se encriptó en la abstracción. (Di Bella, 2008, p. 47)

A través de ellas se enmarcan y expresan una serie de búsquedas conceptuales que unidas al nuevo soporte inician un camino de experimentación perceptual y estética. El espí- ritu de gestación y desarrollo de las vanguardias fueron el alma que dieron la vida a los orígenes del New Media Art, un espacio del arte contemporáneo cuyos cruces de campo comparte, entre otras, las creaciones experimentales del cine, video y TV con la cultura material y estética de nuestro tiempo. El New Media Art se forjó a partir de los primeros descubrimientos ópticos y perceptuales "relacionados con la fotografía en movimiento de fines del siglo XIX como el zootropo (1834), el praxisnoscopio (1877), y el zoopraxiscopio (1879) de Edward Muybridge" (enc.slider.com, 2015). Dieter Daniels define que las bases de esta corriente se fundamentan en una relación de interacción íntima que la sociedad fue construyendo con las condiciones de la tecnología, junto con una idea de arte por fuera de sus límites tradicionales, aspectos que sobreviven hasta hoy en la cultura contemporánea "(...) en los albores del siglo 20, los cimientos se comenzaron a ampliar en un concepto transdisciplinario de arte, un concepto que abarca desde la poesía del futurismo a la composición de color de Delaunay". (Daniels, 2015)

Según Daniels hay dos razones por las que muchos de los artistas de comienzos de siglo XX inician la utilización de los media como soporte de la obra: la primera es este cierto alejamiento expresivo del artista de lo que él denomina sentido común popular, un pasaje vertiginoso del objetivismo al subjetivismo, una cierta elitización de las ideas, recursos y lenguajes, frente al descubrimiento de los media que prometían un alto nivel de impacto y comunicatividad social; la segunda razón fue el nacimiento de un fuerte afán experimental motivado por los descubrimientos de la tecnología, el deseo de mostrar lo nunca visto o lo antes jamás desarrollado, una necesidad de generar asombro y fue sustentando el espíritu de la modernidad. Krasner describe que durante 1920, comenzó en EEUU la industria de las estrellas del cine y la publicidad producidas en masa por Hollywood, donde las películas de género y las de romances reafirmaron valores sociales, familiares y patrióticos, mientras que en Europa (Alemania, Francia y Dinamarca) los cineastas volcados a la animación experimentaban movidos únicamente por el impulso personal de crear arte o Cine puro denominación de las primeras películas abstractas de animación legitimadas por la comunidad artística y que entendieron al film como medio expresivo. (Krasner, 2008, pp. 1-27)

Sin establecer márgenes estrictos, Daniels define algunas etapas asociadas al uso de los media, las dos primeras relacionadas con las llamadas primeras vanguardias o lo que se conoce por Futurismo, Constructivismo, Abstracción, Cubismo, Dadaísmo, entre otras: (1) la utópica hacia 1920 o la etapa de los precursores del arte de media, anterior a la segunda guerra mundial, en la que los artistas recurren a los media con la esperanza de generar un arte social, más comprensible y cercano a las masas populares; (2)otra hacia 1930 donde los artistas se pliegan a un uso político de los media y de los recursos de los comienzos de la propaganda. Daniels puntualiza aquí el paso de la voluntad emancipadora y revolucionaria inicialmente otorgada a los media, hacia otra donde las propiedades de comunicación e impacto fueron utilizadas deliberadamente con fines de implementación política e ideológica del sistema:

\section{(...) Las esperanzas de una función emancipadora de los medios de comunicación se desvanecieron} rápidamente por el uso de propaganda bajo el fascismo y el estalinismo en Alemania, Italia y la URSS. Aquí los artistas de la época pionera como Ruttmann, Vertov, Eisenstein y los futuristas italianos se dedicaron a la propaganda política. Los pioneros de 1920 que emigraron a los EE.UU. tenían muy poca oportunidad de 
continuar su trabajo experimental, pero como Brecht o Fischinger encontraron que todos los formatos de medios no estaban tan fuertemente comercializados.

(3) y una tercera desarrollada con posterioridad a la segunda guerra y concretamente hacia 1960 época de las también llamadas segundas vanguardias como el arte Pop, arte Povera, arte Conceptual, Minimalismo, Objetos específicos, Expresionismo abstracto entre otras, que junto al concepto de mass media fijará en los artistas, una cierta postura crítica, irónica y humorística, respecto al significado socio-político de los media y que sentará las bases espirituales de lo que hoy conocemos como media art o new media art, ideas que se basan en que todo arte que use los media debe ser promovido por una actitud antimedia. Daniels observa que la actitud, opinión y utilización de los media por parte de los artistas de las dos primeras etapas difiere muchísimo de los de la segunda posguerra (tercera etapa). En las dos primeras los artistas consideraban a los media como formas potenciales de arte, posición que paulatinamente fue cambiando hacia otra relacionada con la desilusión, o la sensación de una causa perdida, a medida que los media se vieron cada vez más incorporados e involucrados dentro de los objetivos del comercio, el consumo y la política. Este espíritu inicialmente desilusionado, se expresó a través de una marcada actitud "antimedia, para luego ser una crítica provocativa, humorística e irónica que perdura hasta hoy". (Dieter Daniels en Di Bella, 2008, p. 47)

En una apretada síntesis fueron grandes pioneros de la experimentación de la época de las utopías (1910-30): Filippo Marinetti (1909, Italia) fundador y creador del manifiesto al Futurismo, movimiento literario que se extendió a las artes visuales, que promovía un arte basado en las propiedades de la máquina (energía, movimiento, electricidad, dinamismo, velocidad, etc.). Marcel Duchamp durante su época futurista desarrolló una serie de investigaciones sobre el movimiento, su descomposición, plasmación geométrica, relación con la alquimia, y expresión de un arte maquínico, como parte del espíritu de los artistas del Cabaret Voltaire y padre del dadaísmo y el antiarte, crea Anémic Cinéma(1926) junto a Man Ray, un espiralado continuo de rotor relieves con mensajes sin argumento. Luigi Russolo (Futurismo 1913, Italia) crea el Intonarumorio máquinas de ruido y su manifiesto The art of noise centra la escucha musical en una dimensión experimental, rompe con las convenciones tradicionales de la música, propone un aumento de actividad e interactividad del escuchante, plantea la apertura hacia un pensamiento que integra la máquina y los conceptos de móvil y disponible en un todo con los acontecimientos de la vida cotidiana, einicia un sistema de notación musical que luego será utilizada por loscompositores de música electrónica. Será influencia decisiva para Edgar Varèse o John Cage. Tristán Tzara (1918, Zurich, Alemania) creador del manifiesto al Dadaísmo, parte del grupo del Cabaret Voltaire fundado por Hugo Ball en 1916, propugnaba ideas antiartísticas, antiliterarias y antipoéticas. Walter Ruttmann (1927, Dadaísmo, y Expresionismo Alemán) precursor del cine experimental alemán, de ideología abstracta experimentó el espacio/tiempo y manipulación del film para lograr nuevos lenguajes expresivos. Una de sus películas Berlín, Sinfonía de una ciudad (1927) utiliza conceptos musicales unidos al desarrollo de un sistema propio de montaje que narra los ritmos de la creciente industrialización de Berlín; crea la "Música visual" con Hans Richter y Vikking Eggeling. Velimir Chlebnicov (1921, Futurismo en Rusia) poeta ruso, creador del manifiesto The radio of future, presenta la visión de un modelo utópico o Radio-Eye (radio-ojo) como posibilidad de formación de una comunidad mundial comunicada, un sueño de unión entre las culturas sin distinción de clases, distancias, ni diferencias político-ideológicas, anticipándose a las comunidades en red o comunidad global. Sergei Eisenstein padre del montaje, por sus estudios, experimentaciones y conceptualizaciones acerca de los recursos técnicos en relación con el lenguaje fílmico, su significación, vínculo con la emoción y el poder de la imagen. Dziga Vertov (1925, Rusia) director de cine ruso, iniciador del documental y sus 
experimentaciones con el montaje fílmico y de sonidos en sus reels de Cine Pravda. Vladimir Tatlin y Eliezer Lizzitsky (1922, Constructivismoen Rusia), promovieron un arte (arquitectura, plástica y escultura) unido fuertemente a los conceptos de la abstracción y la geometría, experimentación con materiales nuevos y las ideas de la Escuela Bauhaus. Fernand Léger (1924, Cubismo, Francia) considerado un pintor que vinculó la industria con el arte, comenzó a perseguir al cine y produjo la obra clásica sin guión Ballet Mécanique. Laszló Moholy Nagy (1927, Bauhaus, Alemania) representante del artista polivalente: fotógrafo, cineasta, pintor, escultor, escritor y diseñador gráfico, destaco por el Light Space Modulator: escultura cinética con mecanismos y movimientos impulsados por motores eléctricos que desplegaba acciones en relación con una o varias fuentes luminosas y que arrojaba proyecciones de luces y sombras simultáneas. Daniels menciona que este dispositivo realizado a gran escala podría ser considerado como un anticipo de los primeros conceptos de inmersión. La apertura hacia el audiovisual onírico, plástico, subjetivo y sin coordenadas temporales con Salvador Dali y Luis Buñuel (surrealismo, 1929) Un perro andaluz. Walter Benjamin (1936, Alemania) en su escrito, La obra de arte en la época de la reproducibilidad técnica, expresa la necesidad de generar una nueva expresividad que se distinga del sistema, analiza y describe como las máquinas erigen el valor de una ideología que se va haciendo parte, encarna y altera negativamente la vida social, y advierte de la modificación que sufre la obra de arte cuando es reproducida o duplicada mecánicamente, la que define como una pérdida de unicidad o del aura.

Pertenecen a la segunda (1930-60) y tercera etapa (desde 1960): Walter Benjamin quién define a esta etapa como la ideologización de las utopías y al Fascismo imperante, como un período de estetización de la política (Daniels, 2007). Italia será uno de los sitios en donde los mismos artistas involucrados inicialmente en las utopías futuristas de la primera etapa, se verán seducidos por los recursos y el impacto de la propaganda y pasarán a trabajar para un concepto de arte ligado al ejercicio político, al poder de un sistema y su implementación, en el que la tecnología estará seriamente involucrada. La televisión definirá su papel protagónico cuando en 1936 el Nacional Socialismo transmitió las olimpíadas de Berlín a través de veinticinco estudios de televisión, que juntamente con la radio dieron forma a la idea de la simultaneidad, masividad e impacto a las ideas de poder y progreso que implementaba el sistema. Bertold Brecht en su escrito Radio as Communication Apparatus (1932) asignaba a la radio un carácter revolucionario no como hasta ese momento se la veía, un aparato de distribución, sino como un aparato de comunicación cuya interacción estuviese destinada al progreso social a través de un uso didáctico del media. Oskar Fischinger (pintor, animador, Alemania) precursor de experimentos en la fusión de imagen y sonido como Optical Poem (1938), ayudó a desarrollar el futuro del videoclip. Alexander Alexeieff (Rusia, ilustrador y realizador de cine) y su esposa Claire Parker (EEUU, animadora e ingeniera) patentaron la técnica de animación pin screen (1930-40), que produjo una amplia gama de efectos dramáticos parecidos a grabados, obras creadas con esta técnica Night on Bald Mountain (1933) una adaptación de la pieza musical de Modest Mussorgsky y The Nose (1963), conocida como la secuencia de títulos de apertura de The Trial (1962) de Orson Welles. James Joyce hacia 1938 presenta una novela Finnegans Wake de características inusuales que anticipa el uso del lenguaje de construcción hipertextual a través de un tipo de narrativa que trabaja sobre la evocación del espacio del sueño y la lectura por asociación en distintos niveles, de una colección de intertextos, entre ellos fragmentos de información científica, pasajes de otros textos, dibujos, recortes de revistas y periódicos, canciones, juegos, bromas, mitos, leyendas que generan relaciones entre la ficción, los personajes y la realidad. Len Lye (Nueva Zelanda, artista y escritor) pionero en la técnica de pintura directa sobre película rasgando las imágenes en celuloide de $35 \mathrm{~mm}$, y la creación de esculturas cinéticas, crea Raimbow Dance (1936), Colour flight (1938), Colour Cry (1952) basada en rayogramas, y Free Radicals (1958 / revisada en 1979 a la que le añadió un minuto de footage). 
Siguiendo a Daniels, hacia 1950, después de la segunda guerra mundial, las intenciones de los artistas respecto al uso de los media como soporte de la obra vuelven a punto cero, y esta situación renueva las búsquedas en torno al tema y fija un nuevo comienzo en el uso de la radio, la TV y el film, hacia lo que actualmente se conoce como arte de new media, alrededor de tres estrategias básicas: utópica en manos de Lucio Fontana, otra receptivo-analítica visible en los trabajos de John Cage y una tercera crítica con Guy Debord. Fontana (1951, Italia, Espacialismo) planteará que la televisión debía convertirse en un instrumento en manos de los artistas y comienza a trabajar con la idea de un "concepto espacial" a través de una serie de investigaciones y experimentos en torno a la luz: emisión lumínica, luz de neón, luz negra, pintura fluorescente, realiza instalaciones de neón y redacta el Manifiesto al Espacialismo en TV, en el que revive el espíritu de las utopías de los futuristas italianos. Tal como los futuristas consideraban al ritmo que provenía de las máquinas como la cualidad expresiva de su época, Fontana pensaba en la TV como un dispositivo a través del que se podía hacer un broadcasting de nuevas formas de arte. Los trabajos de Russolo en relación con el ruido, los intonarumori y el Art of noise será de influencia para los trabajos de músicos como John Cage y Edgard Varese. Cage (1950, Estados Unidos) trabajará en el radio art a través de la yuxtaposición de música con ruidos provenientes de emisiones de radio en una misma composición, y tematizará mediante el collage accidental sobre los efectos estéticos de la retransmisión y la percepción del sonido a través de la radio, su producción y consumo. Del mismo modo y siguiendo los desarrollos de Pierre Schaeffer, trabajará sus composiciones a partir de sonidos fuera de contexto y significado connotado en manipulaciones de registro absolutamente anticonvencional, abstracto y experimental, (música concreta, 1948) anticipo de las experimentaciones de música electrónica. Los parámetros de indeterminación musical definidos por Cage que centran al compositor como decidor de la pieza musical dejan por fuera al juicio de la audiencia del mismo modo que la integración del espacio como variable compositiva de Nam June Paik originaron nuevas formas expresivas hacia las instalaciones sonoras y música ambiental. Jan Švankmajer (Checoslovaquia, artista gráfico, escultor, diseñador y poeta) influyó en Tim Burton introdujo un enfoque oscuro, bizarro y grotesco, stop motion de muñecos y objetos, varias capas de animación con fuerte énfasis en la luz, la textura y movimiento de la cámara. Norman McLaren (Escocia, animador y director de cine)se unió al National Film Board de Canadá, admirador del cine de Eisenstein, pionero en la experimentación de pintar sobre celuloide incluso sobre sonido (sonido óptico), uso del pixilation, slowmotion y filme estereoscópico, algunos de sus obras son Dots (1940), Pas de Deux (1968), Synchromy (1971). Por más de cuarenta años produjo películas que le valieron en el mundo animado un reconocimiento. Frank y Caroline Mouris (animadores EEUU) con Frank Cine (1973) desarrolló la técnica de la animación collage en su película ganadora del Oscar. Harry Smith y Robert Breer (EEUU), con Fuji (1974), Bang! (1986) entre otras, se convirtieron en fuerzas en la animación experimental. Guy Debord (1968, Francia, Situacionismo) inicialmente adscribió al Letrismo (ideas anárquicas, 1950) cuyo manifiesto y film Traité de baveet d'eternité de Isidore Isou se proyectó en el Festival de Cannes 1951: dos horas de imagen y sonido de montaje disonante y experimentación fílmica que el público rechazó con muy mala recepción de la crítica. Debord luego de ver el filme lanzará sus críticas contra los postulados de lo que denominó La sociedad del espectáculo (1967), dando origen al manifiesto situacionista, que se erige en contra del capitalismo como generador de una sociedad masivizada por lo industrial, destinada a la descomposición de la cultura, la alienación y la simulación. (Dieter Daniels en Di Bella, 2008, pp. 48-50; Krasner, 2008, pp. 1-27; Marimon, 2014)

Con posterioridad a 1960, las experimentaciones con imagen en movimiento (1970 y 1980) fueron identificadas principalmente con las realizadas en video, y desde 1990 con las prácticas culturales que utilizan tecnología digital como medio de creación, producción, almacenamiento y distribución, basadas en teóricos como Siegfried 
Kracauer, Marshall Mc Luhan, Lev Manovich y sus ideas del cine, la radio y la televisión. Hacia 1963 Nam June Paik presenta trece televisores que exhibían una serie desordenada de latidos y rayas generadas de manera electrónica, sin incluir ninguna imagen real (Exposición Música y Televisión Electrónica, Galería Parnass, Wuppertal) que fijó los parámetros del videoarte: experimentación a partir de elementos mecánicos, cuestionamiento del rito televisivo y del espectador de TV. Considerado el padre del videoarte, se destacó por sus obras experimentales realizadas con emisiones televisivas, video esculturas, instalaciones y perfomance. Otras contribuciones provinieron de Wolf Vostell (grupo Fluxus) con sus decollages electrónicos.

Resulta importante recordar que Paik comparte junto con Jean Tinguely el padrinazgo del Robotic Art, un arte maquínico que traspone lo escultural de la máquina a la construcción del cuerpo, vinculando la sensorialidad con la cinética y la interacción con lo performativo. La idea de cuerpo atravesado o tecnológicamente intervenido -es desde entonces- uno de los aspectos más explorados por las nuevas articulaciones derivadas del mundo digital y la electrónica en relación con el cuerpo en el arte, las artes escénicas, el diseño de interfaces, los videojuegos y los entornos inmersivos (Di Bella, 2008, pp. 48-58). Lev Manovich define las bases de la experimentación digital audiovisual relacionadas con las características del soporte: (a) Sampling consistente en fragmentar el tiempo e inscribir el movimiento; (b) tratamiento del film en código; (c) juego con sonido/ruido análogo y digital; (d) films basados en automatismos o random ready made y (e) Cut and paste espacio temporales; ya que: "todos los objetos new media, ya sean creados directamente en la computadora o convertidos desde fuentes analógicas están compuestos de un código digital: son representaciones numéricas" donde imagen, sonido, texto "son susceptibles de manipulación algorítmica, es decir, se convierten en programables". (Lev Manovich en Morata, 2007, pp. 1-12)

Frente a la deriva digital algunos realizadores experimentales prefirieron continuar con el medio cinematográfico como James Benning (EEUU, cine estructuralista), Rose Lowder (Francia), Robert Beavers (EEUU) entre otros; y muchos otros se abrieron paso a través de las indagaciones, exploraciones y cuestionamientos estéticos a los nuevos medios como Michael Snow y su filme Wavelength (Canadá 1966-1967) que marcó uno de los hitos del cine de vanguardia etiquetada como película estructural; Pat O'Neill (EEUU, 1974) con Saugus Series y otras realizaciones, se lo considera pionero de los efectos ópticos, exploró el cine expandido y las vertientes de la sinestesia; Malcolm Le Grice con Berlin Horse (película estructural, Alemania, 1970) explora según sus palabras:

Las paradojas de las relaciones entre el tiempo real que se vive cuando se realiza el film y el tiempo real que se vive cuando se proyecta el film, así como la forma en que la manipulación técnica de las imágenes y de las secuencias puede modularlo. (Macba, 2006)

Stan Vanderbeek (EEUU, realizador experimental) se convirtió en uno de los más deatacados cineastas por experimentar con los gráficos de computadora y proyección múltiples; Robert Abel (EEUU, animador) pionero en gráficos y efectos visuales por computadora y trabajos de media intercativa, fue contratado por Disney para desarrollar la apertura secuencia de El Agujero Negro (1979) y los gráficos de la película de Disney Tron (1982); John Whitney (EEUU, animador, compositor e inventor) fue un precursor de la animación por computadora en un equilibrio entre ciencia y estética lo que proporcionó vías de aceptación del medio digital como soporte artístico viable; Saul Bass (EEUU, Diseñador gráfico) que participó en la creación de créditos/aperturas de películas, crear el storyboard de la secuencia central de Psicosis de Alfred Hitchcock (1960) en la transmisión del lado oscuro de la psiquis; o Werner Nekes con Diwan (Alemania, 1973) que basándose en los estudios de Dziga 
Vertov, explora la percepción y la unidad mínima asimilable por el ojo humano: el nike (unidad mínima de información audiovisual que para Vertov era de alrededor de dos o tres fotogramas.

Luego de la década del 90 con la furia comercial trasladada a todos los campos del ejercicio profesional, entre ellas las emisoras televisivas, la industria del cine, entretenimiento y videojuegos, y el tratamiento marcario de la comunicación en todas sus formas, junto con el branding y la creación de identidad comercial de productos audiovisuales e interactivos, la experimentación encuentra en la transmedialidad, el diseño y el arte, los espacios legitimados y alternativos de su ejercicio. (Existen otros muchos artistas experimentales destacados que esta síntesis no alcanza a mencionar).

(Marimon, 2014; Morata, 2007, pp. 1-12; Krasner, 2008, pp. 1-27)

Cultura multisensorial. Los sentidos en el foco de la experimentación.

“El sentir ha vuelto a ser para nosotros un problema". (Merleau Ponty, 1945, p. 73)

Según Michel Maffesoli la cultura contemporánea está signada por la presencia de Dionisio (Baco), dios terrenal, del vino, de la naturaleza, como una figura emblemática quién históricamente puede ser definido como el más oriental de los dioses griegos. Bajo este modelo describe a la sociedad actual regida por una serie de variables como el retorno a la naturaleza de origen femenina o la madre tierra, y con ella se instalan sus atributos de sensorialidad, percepción y tribalidad como reflejo de la disolución de la identidad y su fusión en la tribu o viscosidad social. Este estado se traduce en cierto tipo de éxtasis social que se identifica por un excesivo culto al cuerpo, hedonismo, atención a la teatralidad obsesiva de los hechos de la vida, importancia suprema de la moda, adjudicación de valor predominante a la juventud, mixturización de los modos de creación y producción de la imagen, costumbres y tendencias, en un período espiritual de relativización de los supuestos. (Mafessoli en Di Bella, 2011, pp. 124-127)

A partir del arte conceptual, surgido alrededor de 1960-70, se instaura la necesidad de equiparar al concepto con la materialidad de la obra, una resistencia al pensamiento dogmático de la modernidad que planteaba lo que era válido o no en el arte, frente a los condicionamientos de las instituciones del arte y el descubrimiento de la potencia de los procesos seriales, de repetición y de secuencia usados por los medios de comunicación entre ellos la publicidad, la fotografía y el cine. La idea de dispositivo -máquina de hacer o que hace arte- sostén del arte conceptual encontrará en el soporte digital uno de los caminos facilitadores y expresivos al manipular contenidos mensurables en información en un formato ajeno a la expresividad tradicional del arte pero afín con los procesos mentales. (Di Bella, 2008, p. 44). Con la incorporación de la informática y posteriormente la electrónica al campo de la comunicación y del arte, en lo que se denominó inicialmente computer art, se generó una escisión de lo experimental de la historia del cine tradicional "(...) Durante 1960 la divergencia con la historia del cine vino de la mano de las experiencias en videoarte de Nam June Paik y Wolf Vostell, y las perfomances multimediales del grupo Fluxus(...)" (en.slider.com, 2015). Estas experimentaciones condujeron al new media o

\section{(...) fusión progresiva de las vanguardias formalistas, plásticas y musicales, del siglo XX (el abstraccionismo} pictórico en general, el atonalismo de Arnold Schoenberg, Alban Berg y Anton Webern, y el serialismo de Pierre Boulez, Karl Heinz Stockhausen, Luciano Berio Krzysztof Penderecki) con el experimentalismo tecnológico y social propio de artistas de la imagen como Moholy-Nagy, Nam June Paik (especialmente motivado por John 
Cage y Georges Maciunas) y Andy Warhol. Los primeros años del grupo inglés Art \& Language, las estructuras de Sol Lewitt y buena parte del minimalismo norteamericano (Judd, Andre Bochner, Flavin, Michael Heizer, James Turell), las inmersiones vídeo/cine/fotográficas de Douglas Gordon, o aún las pinturas de Blinky Palermo, son otras tantas referencias a tener en cuenta a la hora de describir la genealogía de este nuevo frente tecnológico y generativo de la cultura artística. (Cerveira-Pinto, 2004)

Algunas de las características de la obra experimental posmoderna, se basan en un desmontaje del rito contemplativo, perdida de la sacralización de la obra, cuestionamiento del marco institucional de validación, la combinación de varios sistemas de producción, la construcción de una nueva complejidad perceptual, de técnica y conservación, transposición de lenguajes, puede ser arbitraria, juego de las fronteras entre espectador y el acontecimiento, de concepto espacial, efímera, reproducible, transmisible, ejecutable (sin aura), con debilitamiento de la noción de autoría, y reivindicación temática de las ideas de las minorías y exaltación e integración de la diferencia. (Di Bella, 2011, pp. 124-127). Rodrigo Alonso define que el imaginario temático experimental de producción nacional viene abordando

...desde estéticas muy diversas... un universo híbrido y fragmentario, incompleto e inaprensible... la identidad, la errancia, las contaminaciones estéticas, la mutación de los afectos y las relaciones personales, las nuevas estrategias políticas y económicas, la globalización, las modificaciones del espacio público. (Alonso, 2005)

La caída en la arbitrariedad para algunos tiene su origen en las interpretaciones que algunos artistas conceptuales hicieron de los ready made de Duchamp, que derivaron en la idea de un arte por el arte mismo. En la actualidad la arbitrariedad es una materia posible, necesaria u obligada de la cultura social, normativa, simbólica e ideológica contemporánea, esta cuota sostenida de anarquía alimenta casi todas las producciones artísticas, dada la ruptura entre forma y contenido que suscitó el llamado fin del arte. Con la lógica que instala Duchamp, todas las actividades relacionadas con el arte y la expresividad, de una u otra forma quedan teñidas por su gesto dando paso al experimento como materia inductora y creativa. En síntesis con los medios digitales se abre la posibilidad interactivogestual y el tratamiento de la obra como una categoría de la información, que puede entenderse como un "dispositivo" dispuesto a generar y/o desplegar una instancia del arte, una instalación, intervención o simulacro lúdico, mediático e interactivo, situación que ha cambiado el concepto de la obra y su registro fenomenológico, la expande al universo de la transmisión y circulación masiva, y la extiende hacia el campo de la experimentación y la multiplicidad (Di Bella, 2008, pp. 40-45). Esta articulación de varios sistemas de producción que exploran nuevas relaciones del espacio/tiempo ficcional, narrativo y/o abstracto generan una experiencia que amplifica el rango perceptual hacia la sensorialidad, en una investigación de los límites de la imagen, o lo que Laura Marks define como la experimentación con "la piel del film". Esta imagen se caracteriza por experimentar de manera explícita con la fragmentación, la dispersión, el montaje, no solo desde lo técnico, sino también desde lo cultural e intercultural, lo comercial y lo emergente, lo social y lo individual, lo psicológico y lo subjetivo, en una metodología de comunicación heterogénea que se ve alterada y desplazada por la antinarrativa y la ausencia de un discurso formal, hacia las alteraciones, los intertextos y reconstrucciones de un nuevo texto dirigido a una configuración de relaciones con el público cada vez más orientada hacia la autorreflexividad, la inmersión y la sensualidad (Marks, 2000). La imagen en movimiento se va volviendo compleja y perceptualmente háptica, superando la tradición histórica de la contemplación y las convenciones del arte que vinculaban al hecho estético solo con la visión y la audición. La imagen experimental surge de la indistinción de las fronteras entre el espectador, el relato y el acontecimiento hacia lo que Peter Weibel denominó sistema endofísico, o el estudio donde el observador es parte activa del sistema creado (Weibel, 
2001, p. 23). En el mismo sentido, las nuevas formas de arte ahora denominadas por Nicolás Bourriaud relacionales involucran a la obra en conceptos sistémicos que hacen surgir un nuevo paradigma. Este define que todo aquello que no ingresa dentro de los canales del consumo, incluidas las relaciones interpersonales y sociales, está destinado a desaparecer. Así de este modo las autopistas de la comunicación, los medios electrónicos, los nuevos patrones sociales y simbólicos, las significaciones del mercado y valores derivados del comercio, entre otros serían los nuevos conceptos del juego de relaciones interactivas, sociales y relacionales que establecen los figurantes (consumidores) dentro del nuevo tablero de arte, inserto en las redes del consumo y del comercio "(...) La actividad artística constituye un juego donde las formas, las modalidades y las funciones evolucionan según las épocas y los contextos sociales, y no tiene una esencia inmutable”. (Bourriaud, 2012)

Peeters y Charlier, definen que la sociedad contemporánea se fue cargando de una nueva relación con los objetos en una época en la "que es posible otra relación con el mundo material, objetual, ya no sobre el modo de instrumentación o de alienación, sino sobre el modo de la frecuentación, del contacto o aún de la experiencia afectivo-corporal, incluso del juego (...)", en este plano, la experimentación expresiva de la obra se verá argumentada por el espacio y el atravesamiento del cuerpo (Peeters y Charlier, 1999). Desde 1990 los estudios de media digitales han investigado de manera central la vinculación entre las percepciones y la forma de recepción de los media, sobre todo en los que interviene la realidad virtual, y estos otorgan una preeminencia al uso del cuerpo, desplazando las concepciones visuales tradicionales, e integrando a la percepción visual con lo táctil, la sinestesia y las dimensiones propioceptivas en la construcción mediatizada de los objetos. Muchas de estas investigaciones acerca del acoplamiento de los sentidos relacionadas con lo digital, están vinculadas al estudio del cine y la imagen en movimiento, la influencia de la psicología de la percepción, la teoría literaria, la cultura y la crítica de arte de new media. (Fisher, 1997) Occidente posee una larga historia de estudio de la percepción sustentada en la teoría óptica de la visión. Fueron determinantes la tradición médica (Hipócrates y Galeno. Estudios anatómicos y fisiológicos), la física (Platón y Aristóteles / ciencias naturales, epistemología y psicología) y la matemática (Euclides y Ptolomeo / geometría que deriva la construcción perspectívica del espacio en el renacimiento). Hacia el renacimiento y siguiendo el pensamiento aristotélico, se otorgó a la visión material una relación con la construcción del conocimiento, ya que la vista permitía el acceso directo a las cosas que nos rodean y con las imágenes del pensamiento. (Benéitez Prudencio, 2011, pp. 139-152)

La delimitación de la sensación de lo bello como inicio de la teoría estética (siglo XVIII) y el concepto de arte como práctica es lo que permitirá la autonomía del arte. Esta autonomía dará lugar a la definición de lo exclusivo y excluyente que definirán taxonomías y jerarquizaciones artísticas, entre ellas la de los sentidos. El otorgamiento de un valor exclusivamente estético a la sensación, quedó enmarcado bajo el criterio de las Bellas Artes, a través de las Artes Mayores (Arquitectura, Escultura, Pintura, Música, Teatro y Danza) aprehensibles por la vista y el oído (sentidos mayores o del arte), y las Artes Menores (Artesanía y expresiones populares), posibles de ser percibidas por el gusto, el olfato y el tacto (sentidos menores). Esta configuración naturalizó una distinción entre sentidos que orientaron las asociaciones y connotaciones hacia la polarización entre unos y otros: visible, blanco y bello versus oscuro, negro y feo (maligno), mediadas por los imaginarios culturales y étnicos. En consecuencia se viene presentando en las décadas recientes, producto de las movilidades del paradigma posmoderno, el surgimiento y necesidad de abordar estudios transculturales e interculturales que permitan indagar sobre los caminos de desarticulación y descolonización de postulados y canonizaciones reductivas, segmentadas y/o limitantes. (Gómez de la Errechea Cohas, 2012) 
Laura Marks sostiene que los temas de tratamiento experimental, que surgen en realizadores audiovisuales de contextos interculturales atravesados por visiones de distintas procedencias geográficas y contextuales, contienen atributos de sensorialidad y de corrimiento perceptual respecto de la concepción tradicional de la imagen en la que imperaba la visión como sentido dominante. Si bien no presta atención a la lectura de la diferencia occidental vs. oriental, valora la posibilidad de abarcar mediante la narrativa conceptualformalexpresiva a sentidos no habituales como el tacto, el gusto y el olfato, como medio para despertar la memoria que contiene las codificaciones culturales sensoriales, cultivar el conocimiento y "encontrarse con la cultura dentro del cuerpo", dando cauce a la exploración de las "limitaciones" sensoriales sobre todo a las que parten de los convencionalismos (ver para creer). Sostiene que la construcción histórica de la visión la convirtió en un sentido distanciador entre el cuerpo y el objeto ya que el ojo los abstrae como formas en el espacio y la percepción visual se manifiesta legible, completa y autosuficiente. Basándose en el pensamiento de Henri Bergson sostiene que el cuerpo posee una relación visceral y mimética con el mundo a través de las construcciones de la memoria emocional y cerebral, y que esta memoria es multisensorial. Estas definiciones de Marks conducen hacia las nociones de lo háptico donde los ojos asumen las formas del sentido táctil, y si bien la imagen háptica es menos completa, aporta la construcción de una subjetividad dinámica entre espectador y la imagen. Para asimilar la comprensión de lo háptico versus lo óptico, recurre a la pintura, explicando que la impresión de lo háptico podría ser bien la percepción de un objeto representado de modo impresionista mientras que sería óptica si estuviera representado de modo realista (Marks, 2002). El concepto de la percepción háptica se inicia con Alois Riegl en la segunda mitad del 1800, quién movido particularmente por su ocupación curatorial de telas ornamentales y texturas decorativas, se interesó por aquellas búsquedas perceptuales del arte que incorporaran en un primer plano a la aprehensión táctil o que la equipararan a la visión, generando la primera distinción entre percepción óptica (plana) y táctil (espacial). Walter Benjamín, teórico y pionero del arte cinemático, completa las indagaciones de Riegl, y genera un nuevo concepto que disuelve la distinción inicial, donde articula la percepción óptica (plana) y la háptica (espacial) con la noción de movimiento (tiempo). Giuliana Bruno explica que el nacimiento del cine significó una reformulación del concepto de espacialidad en el arte tradicional, donde la percepción háptica vino a completar la idea de imagen compleja cinematográfica al integrarse con el movimiento. (Bruno, 2002, pp. 247-279)

Resultan interesantes las reflexiones de Marks que llevan a comprender a los sentidos como parte de una endocultura propia dentro de cada cultura específica, lo que implica un entrenamiento selectivo de los sentidos, o previamente orientados por procesos de pertenencia e identidad que construyen una "configuración cultural sensorial específica" que nos aleja de la neutralidad sensorial. Al analizar la experimentación sensorial del cine oriental, expresa que existe un abandono sensual hacia la subjetividad del cuerpo que excluyen visión y audición, posiblemente por la necesidad de opacar el poder del intelecto y dar paso a una noción de respeto y capacidad del cuerpo para proveernos de conocimiento (integración cuerpo-mente), de allí que resulten exaltadas la respiración y las apelaciones olfativas y táctiles, cuya percepción puede resultar exhaustiva y agotadora en occidente. Como consecuencia, Marks define que la experiencia sensorial del cuerpo no puede separarse del conocimiento y que los factores estéticos influyen y afectan la percepción y la cognición, esta noción de estética sensorial integrada es una de las ideas más fuertes que construirían el concepto de lo háptico

Mientras que los privilegios de percepción óptica se apoyan sobre el poder de representación de la imagen, los privilegios de la percepción háptica se sostienen sobre la presencia material de la imagen. Configuraciones de 
otras formas de experiencia de los sentidos, sobre todo con el tacto y lo cinético, la visualidad háptica implica al cuerpo más que la visualidad óptica.

Marks fomenta la relación entre el espectador y la imagen, no desde lo instrumental (lo histórico maquínico) sino lo sensorio, y si bien destina sus investigaciones a la definición de la integración de la percepción, aclara que no tiene ninguna intención de oponer visualidad óptica con háptica, ni condenar a lo óptico "En la mayoría de los procesos de la visión, ambas están involucradas, sería muy difícil observar de cerca la piel de un amante con visión únicamente óptica, como de conducir un auto solamente con la visión háptica”. (Marks, 2002, p. 163)

La conjunción óptico/háptico implica una construcción espacial, siguiendo las ideas de Chrissielles la imagen en movimiento siempre ha transformado el espacio y este proceso de transformación ha sido un principio fundamental de las instalaciones de cine y vídeo desde las prácticas conceptuales de 1960. Estas han generalizado el uso de la proyección de vídeo unido al concepto de instalación espacial, según tres tipos (a) la muy experimentada fenomenológica-performativa (1968-1975), (b) escultórica, utilizada como recursos del cine de los 70 en Hollywood y (c) la convencional o cinematográfica. La fenomenológica, con representantes como Vito Acconci, Bruce Nauman, Donald Judd, Dan Flavin, entre otros, cobró y sigue cobrando aplicación, dado que está inspirada por la teoría de la Gestalt, el conductismo y las ideas acerca de la comprensión del comportamiento humano a través de la relación del individuo con la estructura y dinámica de su situación y entorno (teoría de campo, Kurt Lewin), y que se basó sobre todo en la exploración psicológica (control, poder, dominación) entendiendo a la TV como una máquina cibernética y teledinámica, a través de las acciones del espectador, artista o ambos en tiempo real, poniendo en duda los limites individuales del espacio, el espacio público/privado, experimentos de claustrofobia, saturación perceptual, mimesis, transmisión, videovigilancia, auto-imagen/espejo, introspección, extensión del yo, entre otras muchas. (Chrissie lles, 2000, pp. 252-262)

Como cierre de este artículo, se puede advertir que las experimentaciones pioneras con la imagen en movimiento se han transformado y virado hacia la integración de los entornos virtuales e inmersivos, la interactividad y las comunicaciones por internet en los marcos del soporte. Los planteos espaciales de performance e instalación conceptual originales siguen constituyendo una gran influencia y desafío para las nuevas generaciones de artistas, creadores y realizadores. Los avances y versatilidad de los nuevos soportes, y su impacto sobre las cuestiones de concepto como de la aprehensión y construcción del cuerpo y sensorialidad en el espacio, siguen siendo el foco de las preocupaciones centrales, donde la imagen de video y de cine (análogas o digitales) ya no se expresan en sus formatos más puros sino intervenidas y fusionadas en sus formatos físicos, perceptivos y artísticos. El lugar de la expresividad de la imagen en movimiento ocupa un lugar preponderante donde las variables experimentales se cruzan en muchos sentidos con los cuestionamientos y limitantes epistemológicas de las prácticas, la estética y la historia, como construcciones sociales y culturales que están llamadas a su redefinición en los nuevos contextos posmodernos.

\section{Referencias Bibliográficas}

Akira Mizuta Lippit. (2012). Ex-Cinema: From a Theory of Experimental Film and Video. Berkeley: University of California Press.

Alonso, R. (2006). Arte, Ciencia y Tecnología. Vínculos y desarrollo en Argentina. Cuadernos del Centro de Estudios de Diseño y Comunicación. Ensayos. Facultad de Diseño y Comunicación. Universidad de Palermo. 
Buenos Aires.

Benéitez Prudencio, JJ. (2011). Teorías de la percepción visual y aristotelismo entre los siglos XV y XVII: una aproximación. Albacete: Facultad de Educación. En Ensayos № 26. Disponible en:

http://www.uclm.es/ab/educacion/ensayos

Bruno, G. (2002). An Archive of Emotion Pictures. New York: Verso, 2002. En Atlas of Emotion: Journeys in Art, Architecture, and Film.

Calvera, A. (2005). Arte ¿?Diseño. Nuevos capítulos de una polémica que viene de lejos. Barcelona: Editorial Gustavo Gili. Cerveiro-Pinto, A. (2004). Cognitivo, generativo y dinámico. El arte código y el museo como base de datos. META.morfosis, Proyecto comisariado MEIAC.

Collado Sánchez, E. (2012). Paracinema. La desmaterialización del cine en las prácticas artísticas. Trama Editorial.

Di Bella, D. (2015). La creación escénica como espacio de experimentación. Reflexión Académica en Diseño y Comunicación NXXIV Vol 24. Buenos Aires: Centro de Estudios en Diseño y Comunicación. Facultad de Diseño y Comunicación. Universidad de Palermo.

Di Bella, D. (2011). Territorios de aproximación entre diseño, tecnología y arte. Reflexión Académica en Diseño y Comunicación NXVI Vol 16. Buenos Aires: Centro de Estudios en Diseño y Comunicación. Facultad de Diseño y Comunicación. Universidad de Palermo.

Di Bella, D. (2008). Arte Tecnomedial: Programa curricular. Cuadernos del Centro de Estudios de Diseño y Comunicación, 25, 40-75. Buenos Aires: Centro de Estudios en Diseño y Comunicación. Facultad de Diseño y Comunicación. Universidad de Palermo.

Daniels, D. (2015). Overview of Media Art. Alemania: Ministry of Research and Education (BMBF) comisionado por el Goethe-Institut y el Center for Art and Media Karlsruhe (ZKM). En: Media Art Net. (2015). Disponible en: http://www.medienkunstnetz.de/ themes/overview_of_media_art/forerunners/5/

Daniels, D. (2004). http://www.mediaarthistory.org/maharchive

Fisher, J. (1997). Relational sense: toward a haptic aesthetics. Parachute 87:4-11. Disponible en: http://www.david-howes.com/senses/Fisher.htm

Garavelli, C. (2015). Video experimental argentino contemporáneo. Una Cartografía Crítica. Buenos Aires: Universidad Nacional de Tres de Febrero.

Gómez de la Errechea Cohas, M. (2012). Cartografía hegemónica de los sentidos: la libertad dominada. Brasil. En: Concinnitas. Vol02.

Iles, C. Film and video space. Minneapolis: Universidad de Minnesota. Ed. Erika Suderburg. En: Space, Site, Intervention: Situating Installation Art. 
Krasner, J. (2008). Motion Graphic Design. Applied History and Aesthetics. EEUU: Elsevier.

Macba. (2015). Visionaryfilm.net. AvantGarde Cinema / Experimental Film. Disponible en: http://www.visionaryfilm.net/2006/09/cinemavisin-macba.html

Marimon, J. (2014). El montaje cinematográfico. Del guión a la pantalla. Barcelona: Ediciones Universidad de Barcelona. Marks, L. (2002). Touch: Sensuous Theory and Multisensory Media. Minneapolis: Universidad de Minnessotta Press.

Marks, L. (2000). The Skin of the Film: Intercultural Cinema, Embodiment, and the Senses. Durham: Duke UP. Marzona, D. (2005). Arte conceptual. Bonn, Alemania: Taschen.

Mafessoli, M. (2001). El instante eterno. El retorno de lo trágico en las sociedades postmodernas. Buenos Aires: Paidos Editora.

Morata, M. (2007). Nuevas tecnologías en las artes: cine experimental en la época digital. Reflexiones y propuestas curatoriales. España: Universidad de las Islas Baleares

Peeters, H; Charlier, P. (1999) Introduction. Contribution à une théorie du dispositif. En: Le Dispositif: Entre usage et concept. Hermès, París.

Rajchman, J. (2004). Deleuze un mapa. Ediciones Nueva Visión.

Vattimo, G. (1986). El fin de la modernidad. Nihilismo y hermenéutica en la cultura posmoderna. Barcelona: Editorial Gedisa. Weibel, P. (2001). El mundo como interfaz. Revista Elementos: Ciencia y cultura. №40. Vol7. México: Benemérita Universidad Autónoma de Puebla.

Slider.com (2015). Diccionario en línea. En media art. Disponible en: http://enc.slider. com/Enc/New_Media_art Abstract: This article approaches the aesthetic and sensitive aspects of the experimental.

Key words: postmodernity - culture - image in movement - experimental - paracinema - Rematerialization - new media - aesthetics - Sensoriality - Optical / Haptic.

Resumo: O escrito aborda os aspectos que fazem ao experimental em relação com os aspectos estéticos e sensoriais.

Palavras chave: pós-modernidade - cultura - imagem em movimento - experimental - paracinema - rematerialização - New Media - estética - sensorialidade.

Ex Obra, la rematerialización de la imagen en movimiento fue publicado de la página 95 a página111 en Cuadernos del Centro de Estudios de Diseño y Comunicación № 66 